\title{
Increased Resistance to Several Antibiotics by One Mutation in an R-factor, R 1a
}

\author{
By K. NORDSTRÖM \\ Department of Microbiology, University of Umeå, S-901 87, Umeå 6, Sweden
}

(Accepted for publication 26 March I97I)

\begin{abstract}
SUMMARY
An Hfr strain G I I and an $\mathrm{F}^{-}$strain D I of Escherichia coli K I 2 both containing the R-factor R Ia were treated with ethyl methane sulphonate (EMS). Mutation of the bacteria to high ampicillin resistance occurred at a frequency of $10^{-3}$ to $10^{-4}$ and it was coupled with a simultaneous increase in resistance to chloramphenicol, streptomycin and sulphanilamide. Resistance to all the antibiotics was infective. Increased ampicillin resistance was due to increased penicillinase activity of the bacteria. In a strain containing a mutant R-factor (R I BI) this was due to an increased quantity of an enzyme that seemed to be identical to that of a strain containing the unmutated R Ia. Metabolism of chloramphenicol in strains containing R I B I was greater than in those with R Ia. Mating experiments with an Hfr strain carrying R Ia or R I B I revealed that the two R-factors reduced fertility to about the same extent. Pair formation was two to three times greater in the presence of R I B I than in the presence of R Ia, and R-factor transfer was increased more than chromosome transfer. It is likely that the $\mathbf{R}$ ra genome is read two to three times more efficiently in strains containing the mutated $\mathrm{R}_{\mathrm{I}} \mathrm{BI}_{\mathrm{I}}$, perhaps due to an increased number of copies of the R-factor genome per bacterium.
\end{abstract}

\section{INTRODUCTION}

Resistance to antibiotics may be determined by genes located on episomes ( $\mathrm{R}$-factors). The amount of DNA in these episomes is small (about $\mathrm{I} \%$ of that in the bacterial chromosome), but they have genes which determine resistance to as many as seven antibiotics. Rfactors are transferred from donor to recipient bacteria in a process analogous to conjugation. The transfer is not restricted to single species but can take place between different Enterobacteria (see reviews by Watanabe, 1963, 1967; Datta, I965; Meynell, Meynell \& Datta, 1967; Anderson, 1968; Campbell, 1969). In some cases R-factor mediated resistance has been shown to depend upon metabolism of the drug (Datta, 1965; Okamoto \& Suzuki, 1965). Some of the enzymes such as penicillinases are well characterized; others have been only partly purified.

Ampicillin-resistant mutants of Escherichia coli $\mathrm{K} \mathrm{I} 2$ fall into two classes. Those in class I result from mutation of the $a m p A$ gene. and possess a tenfold increase both in resistance (Eriksson-Grennberg, Boman, Jansson \& Thorén, 1965) and penicillinase activity (Burman, Nordström \& Boman, 1968; Lindström, Boman \& Steele, 1970). AmpA is located close to pur $A$ at $82 \mathrm{~min}$. on the $\mathrm{K} \mathrm{I} 2$ chromosome (Eriksson-Grennberg, I968). Mutants belonging to class II show a twofold increase in ampicillin resistance on agar medium but do not form an increased amount of penicillinase (Boman, Eriksson-Grennberg, Földes \& Lindström, 1967). When $\mathrm{R}$-factors were introduced into $\operatorname{amp} A$ bacteria the ampicillin resistance effect was additive. If an $a m p A$ mutation and $\mathrm{R}$-factors were introduced into mutants of class II yet a further increase of resistance was detected. $R$-factors could therefore be used to identify 
class II mutants, e.g. in analysing the results of crosses (Nordström, Eriksson-Grennberg \& Boman, 1968). The mutation experiments described in this paper show that two sorts of ampicillin-resistant mutants could be obtained from bacteria containing the R-factor $\mathrm{R} I \mathrm{a}$, one which was of the chromosomal class II type and the other which had resulted from mutation in the R-factor. One such mutated R-factor is described in detail. A preliminary report of this work has appeared (Nordström, 1969).

\section{METHODS}

Strains, media and materials. All strains used were derived from Escherichia coli $\mathrm{K} \mathrm{I} 2$ and are listed in Table I. The R-factor R I was obtained from Dr Datta (Meynell \& Datta, 1966) and the derepressed mutant R I $d r d-19$ (Meynell \& Datta, I967) from Dr Meynell; R I normally confers resistance to ampicillin, chloramphenicol, kanamycin, streptomycin and sulphonamides. Resistance to kanamycin is easily lost (N. Datta, personal communication) and our R I was only resistant to the other four antibiotics. It was given the symbol $\mathrm{R} I a$.

Table I. Strains of Escherichia coli $\mathrm{K} \mathrm{I} 2$ used

\begin{tabular}{|c|c|c|c|c|c|c|}
\hline \multirow[b]{2}{*}{ Strain } & \multirow[b]{2}{*}{ Origin } & \multirow[b]{2}{*}{ Sex } & \multicolumn{3}{|c|}{ Ampicillin resistance } & \multirow[b]{2}{*}{ Other markers $\dagger$} \\
\hline & & & Class & Phenotype* & Genotype & \\
\hline G I I & Stent \& Brenner (1961) & Hfr & wt & Amp-s & wt & $m e t B, i l v$ \\
\hline G I I al & $\begin{array}{l}\text { Eriksson-Grennberg } \\
\text { et al. (1965) }\end{array}$ & Hfr & $\mathbf{I}$ & Amp-10 & $\operatorname{ampA}$ & metB, ilv \\
\hline GII eI & $\begin{array}{l}\text { Eriksson-Grennberg } \\
\text { et al. }(1965)\end{array}$ & $\mathrm{Hfr}$ & II & Amp-20 & $\begin{array}{l}\operatorname{amp} A+\text { an } \\
\text { additional } \\
\text { mutation }+\end{array}$ & met $B$, ilv \\
\hline D I & $\begin{array}{l}\text { RC711 of Meynell \& } \\
\text { Datta (I966) }\end{array}$ & $\mathbf{F}^{-}$ & wt & Amp-s & wt & his, proB, trp \\
\hline DII & $\begin{array}{l}\text { Boman, Eriksson- } \\
\text { Grennberg, Normark \& } \\
\text { Matsson (1968) }\end{array}$ & $\mathbf{F}^{-}$ & wt & Amp-s & wt & $h i s$, proB, trp, str \\
\hline
\end{tabular}

* Defined by Nordström et al. (1968); the figure indicates the factor by which the wild-type resistance (Amp-s) is increased.

$\dagger$ Abbreviations: amp, ampicillin; his, histidine; met, methionine; ilv, isoleucine-valine; pro, proline; str, streptomycin; trp, tryptophan; wt, wild-type.

\$. See Nordström et al. (1 969$)$.

The minimal medium E of Vogel \& Bonner (1956) and the complete medium LB of Bertani (I95I) were used, the latter containing $0.2 \%$ glucose $(w / v)$. Solid medium was obtained by the addition of $\mathrm{I} \cdot 5 \%$ agar; that derived from LB medium was called LA. All experiments were performed at $37^{\circ}$, and growth was determined by reading extinction with a Klett colorimeter using filter W66. A reading of 100 Klett units corresponds to $4 \times 10^{8}$ bacteria/ml. when grown in LB medium.

DL-Ampicillin (ratio between the epimers $4: 6$ ) and D-ampicillin were obtained from Astra, Södertälje, Sweden; chloramphenicol as the free base and streptomycin sulphate from Kabi, Stockholm, Sweden; ethylmethane sulphonate (EMS) from Eastman Organic Chemicals (Eastman grade, catalogue no. 7830); and kanamycin from AB Ferrosan, Malmö, Sweden. The microculture containers used for replica plating were obtained from Elesa, Milan, Italy.

Induction of mutations. The bacteria were grown in LB at $37^{\circ}$ on a rotary shaker to a density of about $4 \times 10^{8}$ organisms $/ \mathrm{ml}$., EMS was added to a final concentration of $10 \mu 1 . / \mathrm{ml}$. and incubation continued for $2 \mathrm{~h}$. The cultures were centrifuged, washed twice with 
$0.9 \%(w / v) ~ N a C l$ and suspended in fresh LB. Incubation was continued for further $2 \mathrm{~h}$. to allow phenotypic expression.

Transfer of $R$-factors and chromosomal markers. The procedure for the transfer of the $\mathrm{R}$-factor R I was as described by Nordström et al. (1968). In mating experiments $2 \times 10^{7}$ donor and $2 \times 10^{8}$ recipient bacteria $/ \mathrm{ml}$. grown in LB and harvested in the log phase were mixed, incubation continued and mating interrupted by blending on a Vortex mixer. Different dilutions of the mating mixture in $0.9 \% \mathrm{NaCl}(\mathrm{w} / \mathrm{v})$ were spread on selective medium and those giving 40 to 400 colonies/plate were used to calculate the frequencies shown in Fig. 4 and 5 .

Pair formation was measured in a mating procedure as described by de Haan \& Gross (1962); $2 \times 10^{7}$ donor and $2 \times 10^{8}$ recipient bacteria $/ \mathrm{ml}$. were mixed and $5 \mathrm{~min}$. allowed for pairing. The culture was then diluted I0o-fold with prewarmed medium to prevent further pair formation. Samples were taken at intervals, shaken to separate pairs and spread on selective medium. The plateau value obtained is a measure of the number of pairs formed initially.

Transduction with phage P I was as described by Eriksson-Grennberg (1968).

Drug resistance. Preliminary tests were carried out by replica plating onto LA medium containing the drug. Due to the high penicillinase activity associated with the R-factors, it was necessary to dilute the inocula to less than 100 bacteria per spot. In single organism tests the bacteria were grown in LB to a density of $4 \times 10^{8} / \mathrm{ml}$, diluted $10^{-5}$ in $0.9 \%(\mathrm{w} / \mathrm{v})$ $\mathrm{NaCl}$, and $0^{\circ} \mathrm{I} \mathrm{ml}$. plated on LA plates containing different concentrations of antibiotics. The colonies formed were counted after incubation overnight and the resistance level is given as the highest concentration of antibiotics at which the colony count was the same as that of the control (Nordström et al. 1968). Tests for resistance to sulphanilamide were done on solid minimal medium.

Penicillinase was determined by means of Novick's (1962) micro-iodometric method adapted to the AutoAnalyzer (Burman et al. 1968).

The same paper disc method and the strain of Sarcina lutea was used as described previously for the determination of the destruction of penicillin. (Burman et al. 1968). Chloramphenicol in the concentration range 2 to $30 \mu \mathrm{g} . / \mathrm{ml}$. could also be determined with this method, i.e. the sensitivity was the same for chloramphenicol as for ampicillin.

The procedure used to purify the R I penicillinase was as described by Lindqvist \& Nordström (I970).

\section{RESULTS}

\section{Isolation of strains with higher resistance}

The R-factor R Ia was introduced into G I I and D I, giving strains G I I-R Ia and D I-R Ia respectively. Log-phase cultures of the two latter strains containing $4 \times 10^{8}$ bacteria $/ \mathrm{ml}$. were treated with Io $\mu \mathrm{l}$. EMS $/ \mathrm{ml}$. and then spread on LA plates containing DL-ampicillin at different concentrations as described in the legend to Fig. I. Untreated cultures were used as controls and the survival curves obtained are shown in Fig. I. For both strains, EMS treatment yielded a higher proportion of clones with high resistance; $\mathrm{IO}^{-3}$ to $\mathrm{IO}^{-4}$ of the surviving bacteria as compared with $1 \mathrm{O}^{-5}$ to $\mathrm{IO}^{-6}$ from the untreated cultures. Clones were picked from plates containing $500 \mu \mathrm{g}$. $/ \mathrm{ml}$. of DL-ampicillin and purified by restreaking on plates containing the same concentration of ampicillin.

The clones isolated as resistant to $500 \mu \mathrm{g}$. $/ \mathrm{ml}$. of DL-ampicillin were tested for resistance to ampicillin and chloramphenicol at different concentrations by replica plating. The results together with the resistance levels of the parental strains are given in Table 2 . The Hfr strain G I I-R Ia and the F- strain D I-R Ia behaved similarly and two classes of mutants 
both showing parallel increased resistance to chloramphenicol were obtained. The clones obtained after EMS treatment showed a considerable increase in resistance, while without EMS treatment clones of lower resistance resembling class II strains were isolated (cf. strain GIIeI-R Ia in Table 2).

When clones were selected at higher concentrations of DL-ampicillin several classes of mutants were obtained. The higher the concentration of the antibiotic, the higher the resistance of the surviving clones. A small number of clones with different levels of resistance were tested for penicillinase production. Since it was shown (see below) that they were mutated in the R-factor they were denoted D I-R I B I, etc. Table 3 shows that they possessed different penicillinase activities and that the activity was correlated with resistance.

When subcultured, bacteria from the most resistant clones were found to be rather unstable and they reverted to $\mathrm{R}$ Ia resistance or to an intermediate level. However, some of

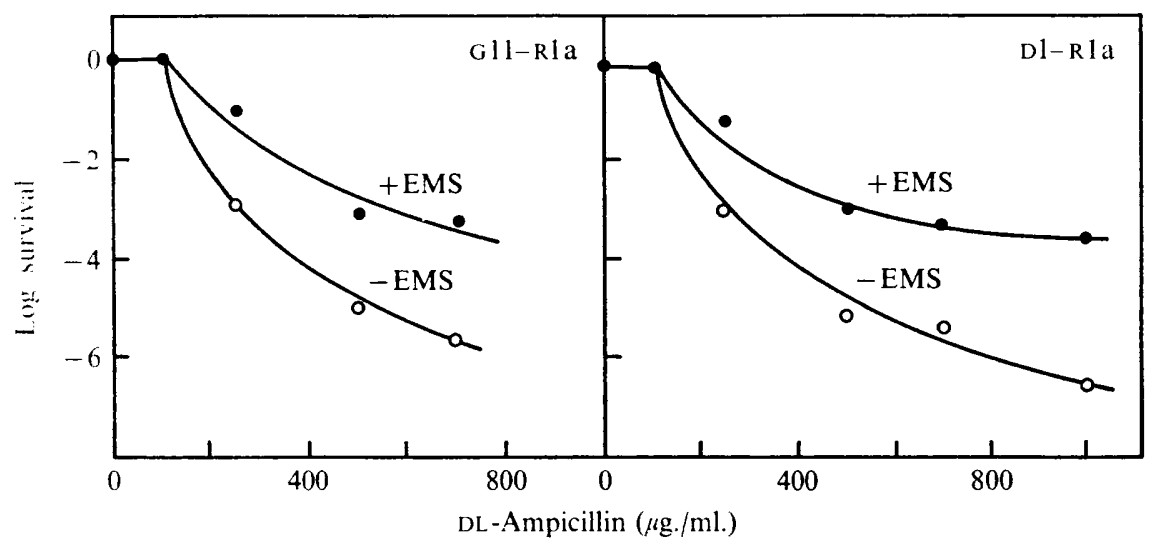

Fig. I. Mutation of strains G I I-R Ia and DI-R I a to higher ampicillin resistance. Experimental conditions were as described in Methods. Different dilutions were then spread on LA containing different concentrations of DL-ampicillin (abscissa). The number of colonies were counted after incubation overnight and those dilutions that gave 20 to 200 colonies per plate were used to calculate survival.

\section{Table 2. Resistance to ampicillin and chloramphenicol of mutants picked as resistant to $500 \mu \mathrm{g} . / \mathrm{ml}$. of DL-ampicillin}

Bacteria were grown in LB at $37^{\circ}$ on a rotary shaker to a density of about $4 \times 10^{8}$ orgs./ml., EMS added to a final concentration of $10 \mu \mathrm{l} . / \mathrm{ml}$. and incubation continued for $2 \mathrm{~h}$. The cultures were centrifuged, washed twice with $0.9 \%(w / v) ~ N a C l$ and suspended in fresh LB. Incubation was continued for a further $2 \mathrm{~h}$. to allow phenotypic expression. Different dilutions were spread on LA containing $500 \mu \mathrm{g}$. of DL-ampicillin/ml. From those plates that gave 20 to 200 colonies a number of clones were picked, purified by restreaking on LA and tested for resistance by replication.

\begin{tabular}{|c|c|c|c|c|c|}
\hline \multirow[b]{2}{*}{ Strain } & \multicolumn{2}{|c|}{ Treatment } & \multirow{2}{*}{$\begin{array}{l}\text { No. of } \\
\text { clones } \\
\text { tested }\end{array}$} & \multicolumn{2}{|c|}{ Resistance $(\mu \mathrm{g} . / \mathrm{ml})}$. \\
\hline & EMS & $\begin{array}{l}\text { Ampicillin } \\
\text { plates }\end{array}$ & & Ampicillin & $\begin{array}{l}\text { Chloram- } \\
\text { phenicol }\end{array}$ \\
\hline \multirow[t]{3}{*}{ DI-R Ia $\left(\mathrm{F}^{-}\right)$} & - & - & I (parent) & 200 & 200 \\
\hline & - & + & 32 & 400 & 400 \\
\hline & + & + & 37 & $\geqslant 700$ & $\geqslant 600$ \\
\hline \multirow[t]{3}{*}{ GII-R Ia (Hfr) } & - & - & I (parent) & 200 & 200 \\
\hline & - & + & 34 & 400 & 400 \\
\hline & + & + & 35 & $\geqslant 700$ & $\geqslant 600$ \\
\hline GIIeI-RIa (Hfr) & - & - & I (parent) & 400 & 400 \\
\hline
\end{tabular}


the mutant R-factors were found to be stable and one of them, R I B I, was studied further. It was transferred from $D$ I to $G$ I I strains and tested for resistance to all four antibiotics by the single organism test. The results in Table 4 show that resistance to all four antibiotics was increased severalfold. This led to the conclusion that the mutation resulting in increased resistance was located in the episome. In this table the resistance pattern given by Datta's derepressed R-factor R I $d r d-I 9$ is also included since the R-factor R I B I could have been a regulatory mutant of $\mathbf{R} I a$.

\section{Table 3. Penicillin resistance and penicillinase activity of strain D I containing EMS-induced mutations in the episome $R I a$}

Six of the mutant clones obtained from DI-R Ia in the experiment described in Table 2 were tested for ampicillin resistance by single organism test on LA plates and for penicillinase activity in the AutoAnalyzer.

\begin{tabular}{|c|c|c|}
\hline Strain & $\begin{array}{l}\text { DL-Ampicillin } \\
\text { resistance } \\
(\mu \mathrm{g} . / \mathrm{ml} .)\end{array}$ & $\begin{array}{c}\text { Penicillinase } \\
\text { activity } \\
\text { (units } / \\
\text { I0 } 0^{9} \text { bacteria) }\end{array}$ \\
\hline D I-R Ia & 200 & $2 \cdot 9$ \\
\hline D I-R I B I & 600 & $5 \cdot 8$ \\
\hline D I-R I B 2 & 500 & $4 \cdot 8$ \\
\hline D I-R I B 3 & 700 & $6 \cdot 9$ \\
\hline D I-R I B 4) & & $12 \cdot 5$ \\
\hline DI-RI B 5 & $\geqslant 1000$ & I 4.8 \\
\hline D I-R I B 6$)$ & & $22 \cdot 0$ \\
\hline
\end{tabular}

Table 4. Resistance pattern of R-factor strains

Resistance was tested by single organism tests on LA plates.

\begin{tabular}{lcccc}
\multicolumn{4}{c}{ Resistance on plates $(\mu \mathrm{g} . / \mathrm{ml})}$. & Str \\
Gtrain & D-Amp & Cml & Sul \\
G I I-R I I B I & 75 & 300 & 15 & 300 \\
G I I-R I drd-I9 & 200 & 800 & 40 & 1000
\end{tabular}

Abbreviations used: Amp, ampicillin: Cml, chloramphenicol; Str, streptomycin; Sul, sulphanilamide.

To demonstrate that this mutation could be transferred by infection the clones described in Table 2 were tested for transfer of resistance to an $\mathrm{F}^{-}$recipient. Mutants of both the Hfr strain GII-R Ia and the $F^{-}$D I-R Ia were tested as donors. All strains isolated after EMS treatment transferred resistance to high concentrations of antibiotic, while the untreated strains conferred only the lower level of resistance of the parental strain R Ia. This confirmed that the EMS-induced mutations were located in the R-factor. Without EMS treatment the mutants isolated were of class II, i.e. similar to strain G I IEI-R Ia (Table 2) which is mutated in the chromosome (Nordström et al. 1968; Nordström, Burman \& Eriksson-Grennberg, 1969).

\section{Comparison of resistance conferred by $\mathrm{R} I a$ and by $\mathrm{R} I B I$}

Resistance to ampicillin and chloramphenicol was also tested in liquid medium. Strains G I I-R I a and G I I-R I B I were grown in LB medium to a density of about $10^{8}$ organisms $/ \mathrm{ml}$. DL-Ampicillin or chloramphenicol was added, incubation continued and the extinction of the cultures recorded. The results are plotted in Fig. 2 and 3 and they show that the mutated $\mathrm{R}$-factor mediated a considerably increased resistance to the two drugs tested as compared 
to R Ia; GII without any R-factor does not grow even in the presence of $10 \mu \mathrm{g} / \mathrm{ml}$. of ampicillin or chloramphenicol. Also at concentrations of ampicillin or chloramphenicol that inhibited the growth of both strains, growth was resumed much more rapidly by G I IR I B I than by G I I-R Ia. Such curves are normally interpreted as an indication that the drug tested is being broken down. In a bioassay using Sarcina lutea it was shown that the strain G I I-R I B I broke down chloramphenicol about twice as rapidly as did strain GII-R Ia. The penicillinase activity of strain GII-R I B I was much greater than that of GII-R Ia (Table 3).

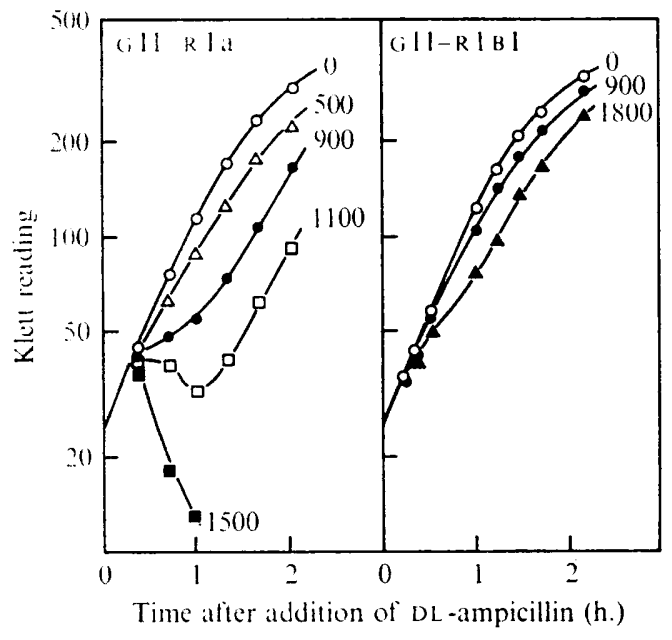

Fig. 2

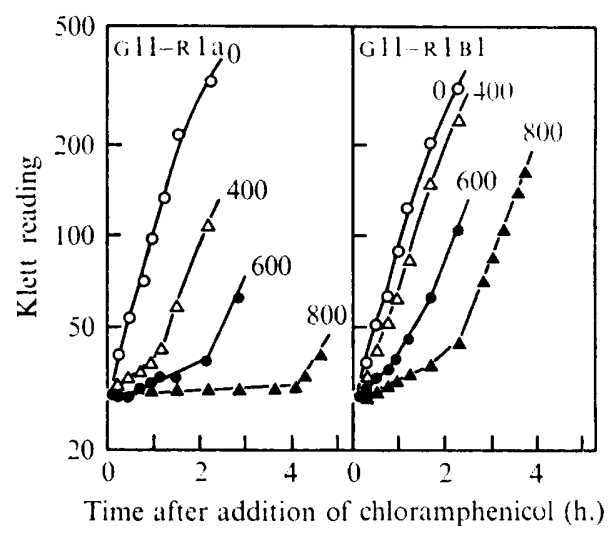

Fig. 3

Fig. 2. Effect of ampicillin on growing cultures of G I I-R I a and G I I-R I B I. The strains were grown in LB medium. Ampicillin was added when the cultures contained $10^{8}$ organisms $/ \mathrm{ml}$., incubation was continued and the extinction was read at intervals over a period of $2 \mathrm{~h}$. The concentrations of ampicillin used are given in $\mu \mathrm{g} . / \mathrm{ml}$. in the figure.

Fig. 3. Effect of chloramphenicol on growing cultures of G I I-R I a and G I I-R I B I. Experimental conditions were as described in Fig. 2.

\section{Purification of penicillinase}

The penicillinase produced by the R-factor R Ia has been purified (Lindqvist \& Nordström, 1970) and it is very similar to the enzyme produced by R I B I. The most important finding is that the turnover numbers are the same for the two enzymes and that the amount of the enzyme per bacterium was doubled by the mutation.

\section{Sex properties of bacteria carrying $R I a$ and $R I B I$}

The mating characteristics of strains carrying the R Ia and the mutated R I B I factors were compared. Fig. 4 shows the effect of each of the two R-factors on the transfer of an early gene ( $p r o B^{+}$) from Hfr G I I to the $\mathrm{F}^{-}$strain D II. Both R-factors greatly reduced the transfer of chromosomal genes and it was necessary to multiply the numbers of recombinants obtained in crosses in which the donor contained an R-factor by 10 in Fig. 4. Nevertheless, pro $B^{-}$transfer by strain GII-RI B I was about twice that for GII-R Ia. Recombinants obtained in the two crosses were also tested for cotransfer of episomal markers with chromosomal genes. In both cases, 46 proB $^{+}$recombinant clones obtained after a mating time of $40 \mathrm{~min}$. were purified and tested by replica plating. The first cross (D I I $\times$ G I I-R I B I) gave no cotransfer of resistance with ${\text { pro } B^{+}}^{+}$while two cases appeared in the latter (D II $\times$ 
G I I-R Ia). There was a slightly delayed entry in the crosses in which donor contained R-factors (Fig. 4). The significance of this is not understood.

In the same experiment as that reported in Fig. 4 the kinetics of the transfer of antibiotic resistance from GII-RIa and GII-RIBI to the recipient DII was also studied. As is apparent from Fig. 5, the transfer of the mutated R-factor R I B I was about Io times as efficient as that of R Ia. This means that pair formation was more efficient with G I I-R I B I than with G I I-R Ia.

Using a more direct measure of pair formation (de Haan \& Gross, I962) R I B I gave two to three times more pairs than R Ia (Table 5). Furthermore, R-factor transfer was much greater once pairs had been formed.

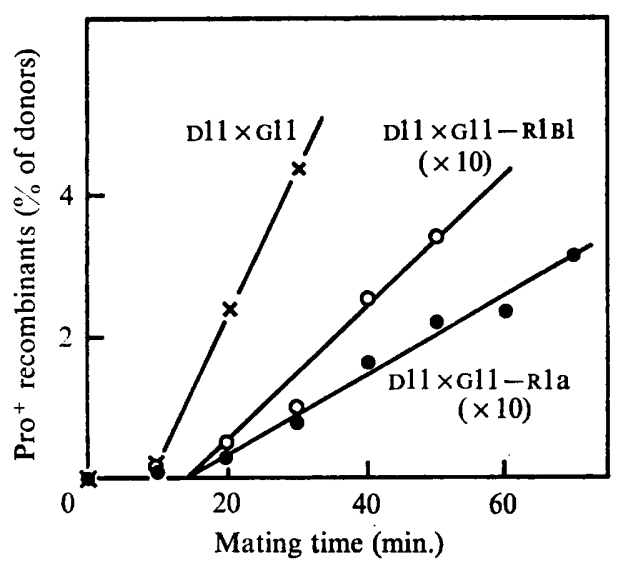

Fig. 4

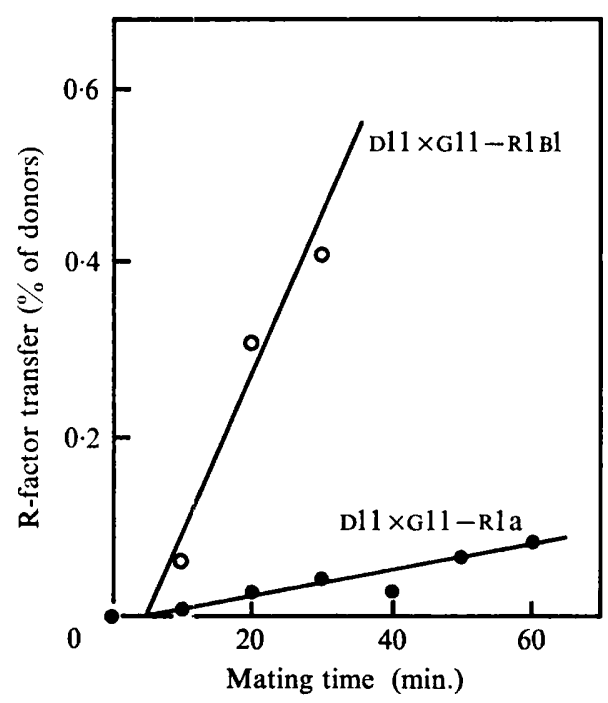

Fig. 5

Fig. 4. Kinetics of the formation of proB $^{+}$recombinants in crosses between the $\mathrm{Hfr}$ strain $\mathrm{GII}$ without and with $\mathrm{R}$-factors and the $\mathrm{F}^{-}$strain $\mathrm{DII}$. Donor $\left(2 \times 10^{7} / \mathrm{ml}\right.$.) and recipient bacteria $\left(2 \times 10^{8} / \mathrm{ml}\right.$.) were mixed and incubated without agitation at $37^{\circ}$. At intervals samples were shaken vigorously to break all pairs and plated on selective medium with streptomycin $(100 \mu \mathrm{g} . / \mathrm{ml}$.) to eliminate the donor. The number of recombinants from crosses in which the donor contained an $R$-factor have been multiplied by 10 .

Fig. 5. Kinetics of transfer of the R-factors $R$ ra and $R_{I} B_{I}$. The experiment was as described in Fig. 4. Selection was made on minimal medium plus the amino acids required by the recipient. Chloramphenicol (100 $\mu \mathrm{g} . / \mathrm{ml}$.) was used to eliminate the recipient cells which had not received the R-factor.

\section{Table 5. Pair formation with strains containing $R$-factors}

Matings were carried out by the method of de Haan \& Gross (1962). The table gives the frequencies of recombinants when plateau values were reached.

Plateau values ( $\%$ of donor) for transfer of

\begin{tabular}{lccc}
\multicolumn{1}{c}{ Cross } & proB & R-factor & Sum \\
DII X GII & 2.10 & - & 2.10 \\
DII XGII-R Ia & 0.06 & 0.02 & 0.08 \\
DII X GII-RI BI & 0.10 & 0.18 & 0.28
\end{tabular}




\section{Transduction experiments}

Phage PI grown on GII-R Ia and GII-R I B I was used in transduction of strain DII. Chloramphenicol resistance ( $100 \mu \mathrm{g} . / \mathrm{ml}$.) was used to select for transductants that had received R-factors. In both experiments $\mathrm{I} 00$ chloramphenicol-resistant transductants were purified and their resistance to ampicillin, chloramphenicol, streptomycin and sulfonamide determined by replica plating. There was no indication of any segregation of the resistance genes. Furthermore, transduction with P I (G I I-R I B I) gave the higher resistance characteristic for strains carrying the mutated R-factor while P I (G I I-R Ia) gave the lower resistance level (see Table 4).

\section{DISCUSSION}

The results of the experiments described in this paper indicate that EMS induces mutations in the R-factor resulting in infective transfer of resistance to high drug concentrations. Similar findings have been reported for Salmonella typhi by Sompolinsky, Ben-Yakov, Aboud \& Boldur (1967) but they do not discuss transfer of resistance to more than one antibiotic. Pearce \& Meynell (1968) have described mutants of R I giving increased resistance to streptomycin. In the work described in this paper resistance to four antibiotics were affected simultaneously. From Table 4 it can be concluded that the mutation in R I B I increases the amount of resistance gene products per bacterium for all four resistance genes carried by $\mathrm{R}$ Ia. Furthermore, genes involved in pair formation and gene transfer also seem to function more efficiently (Table 5).

The mutation could work either by altering the number of gene copies per cell or at the transcription level. The derepressed R-factor of Meynell \& Datta (1967) did not cause any change in resistance pattern (Table 4). Fifty per cent of donor bacteria transfer this $\mathrm{R}$-factor. Thus it is suggested that the R-factor genome can be functionally divided into at least two parts (operons?) of which the RTF (resistance transfer factor) has its own regulation. It is difficult to understand why the transfer of the R-factor should increase more than the transfer of chromosomal markers if the mutation through altered transcription increased piliation of Hfr bacteria.

An alteration in the number of gene copies per bacterium could be achieved in two ways, either by polymerization of the $\mathrm{R}$-factor or by altered regulation of the replication of the $\mathrm{R}$-factor resulting in an increased number of unchanged $\mathrm{R} \mathrm{I}$-factors per bacterium. EMS is known to induce chromosome abberations of various kinds, e.g. mitotic recombination in yeast (Yost, Chaleff \& Finerty, 1967), and it is possible that this mutagen may induce the formation of polymers of R-factors. Datta (1965) has shown that R $\mathrm{I}$, which is of the $f^{+}$ type, codes for the same type of pili as does the F-factor. Thus once a mating pair was formed the probability of transferring the R-factor or the chromosome will most likely be a function of the number of copies of each replicon per bacterium. The transfer of the $R$ factor itself was increased more by the mutation giving R I B I from R I a than the transfer of the chromosomal marker proB $B^{+}$(Fig. 4, 5 and Table 5). Thus for $\mathrm{R}_{\mathrm{I}} \mathrm{B}$ I an increased number of free $\mathrm{R}$-factor copies is more likely than a polymer $\mathrm{R}$-factor. The results of the transduction experiments also favour this conclusion, as a polymer of $\mathrm{R}$ Ia would presumably be too large to be transduced in one piece. Rownd, Nakaya \& Nakamura (I966) have shown that the number of copies of $\mathrm{R}$-factor per chromosome is different in different species.

Mutants such as R I B I may be of value in studying the number of operons in R-factors and also of regulation of the number of episomes per bacterium. 
I thank Mr C. Lindqvist for his help with enzyme purification and acknowledge the skilful technical assistance of Miss Britt Hansson. This work was supported by grants $68: 44$ and 69:47 from the Swedish Cancer Society.

\section{REFERENCES}

ANDERSON, E. S. (1968). The ecology of transferable drug resistance in the Enterobacteria. Annual Review of Microbiology 22, I3I-I80.

BeRTANI, G. (I951). Studies on lysogenesis. I. The mode of phage liberation by lysogenic Escherichia coli. Journal of Bacteriology 62, 293-300.

Boman, H. G., ERIKSSON-GrenNBerg, K. G., FöLDES, J. \& LindSTRöM, B. (1967). The regulation and possible evolution of a penicillinase-like enzyme in Escherichia coli. In Regulation of Nucleic Acid and Protein Biosynthesis, vol. 10, pp. 366-372. Edited by V. V. Koningsberger \& L. Bosch. Amsterdam: Elsevier Publishing Co.

Boman, H. G., Eriksson-Grennberg, K. G., Normark, S. \& Matsson, E. (I968). Resistance of Escherichia coli to penicillins. IV. Genetic study of mutants resistant to DL-ampicillin concentration of $100 \mu \mathrm{g} . / \mathrm{ml}$. Genetical Research 12, 169-185.

Burman, L. G., Nordström, K. \& Boman, H. G. (1968). Resistance of Escherichia coli to penicillins. V. Physiological comparison of two isogenic strains, one with chromosomally and one with episomally mediated ampicillin resistance. Journal of Bacteriology 96, 438-446.

CAmpbell, A. M. (1969). Episomes. New York: Harper \& Row.

DatTA, N. (1965). Infectious drug resistance. British Medical Bulletin 21, 254-259.

ERIKSSON-GRENNBERG, K. G. (1968). Resistance of Escherichia coli to penicillins. II. An improved mapping of the ampA gene. Genetical Research 12, 147-156.

Eriksson-Grennberg, K. G., Boman, H. G., Jansson, J. A. T. \& Thorén, S. (1965). Resistance of Escherichia coli to penicillins. I. Genetic study of some ampicillin-resistant mutants. Journal of Bacteriology 90 , 54-62.

DE HAAN, P. G. \& GRoss, J. D. (1962). Transfer delay and chromosome withdrawal during conjugation in Escherichia coli. Genetical Research 3, 25I-272.

LiNDQVist, R. C. \& NoRDSTRÖM, K. (1970). Resistance of Escherichia coli to penicillins. VII. Purification and characterization of the penicillinase mediated by the R-factor R I. Journal of Bacteriology ror, 232239.

Lindström, B., Boman, H. G. \& Steele, B. (1970). Resistance of Escherichia coli to penicillins. VI. Purification and characterization of the chromosomally mediated penicillinase present in amp $A$ containing strains. Journal of Bacteriology 101, 218-231.

Meynell, E. \& Datta, N. (1966). The relation of resistance transfer factors to the F-factor (sex-factor) of Escherichia coli K I2. Genetical Research 7, I34-140.

MeYNeLl, E. \& DatTA, N. (1967). Mutant drug-resistant factors of high transmissibility. Nature, London 214, 885-887.

Meynell, E., Meynell, G. G. \& Datta, N. (1967). Phylogenetic relationship of drug resistance factors and other transmissible bacterial plasmids. Bacteriological Reviews 32, 55-83.

NoRDSTRÖM, K. (I969). A mutated R-factor mediating increased resistance to several antibiotics. Journal of General Microbiology 57, xxxi-xxxii.

Nordström, K., Burman, L. G. \& Eriksson-GrennBerg, K. G. (1969). Resistance of Escherichia coli to penicillins. VIII. Physiology of a class II ampicillin-resistant mutant. Journal of Bacteriology 1or, 659668.

Nordström, K., ERIKSSON-Grennberg, K. G. \& Boman, H. G. (1968). Resistance of Escherichia coli to penicillins. III. $A m p B$, a locus affecting episomally and chromosomally mediated resistance to ampicillin and chloramphenicol. Genetical Research 12, 157-168.

Novick, R. P. (1962). Micro-iodometric assay for penicillinase. Biochemical Journal 83, 236-240.

Окамото, S. \& SUZUKI, J. (1965). Chloramphenicol, dihydrostreptomycin and kanamycin inactivating enzymes from multiple drug-resistant $E$. coli carrying episome ' $R$ '. Nature, London 208, I $30 \mathrm{I}-\mathrm{I} 303$.

PeARCE, L. E. \& MeYNell, E. (1968). Mutation to high-level streptomycin resistance in $\mathbf{R}^{+}$bacteria. Journal of General Microbiology 50, 173-176.

Rownd, R., NaKaya, R. \& Nakamura, A. (1966). Molecular nature of the drug resistance factors of the Enterobacteriaceae. Journal of Molecular Biology 17, 376-393. 
Sompolinsky, D., Ben-Yakov, M., Aboud, M. \& Boldur, I. (1967). Transferable resistance factors with mutator effect in Salmonella typhi. Mutation Research 4, I19-1 27.

Stent, G. S. \& Brenner, S. (I96I). A genetic locus for the regulation of ribonucleic acid synthesis. Proceedings of the National Academy of Sciences of the United States of America 47, 2005-20r4.

VOGEL, H. J. \& BONNER, D. M. (1956). Acetylornithase of Escherichia coli: partial purification and some properties. Journal of Biological Chemistry 218, 97-106.

WATANABE, T. (1963). Infective heredity of multiple drug resistance in bacteria. Bacteriological Reviews 27, 87-115.

WATANABE, T. (1967). Evolutionary relationships of R-factors with other episomes and plasmids. Federation Proceedings. Federation of American Societies for Experimental Biology 26, 23-28.

Yost, H. Y. Jun., Chaleff, R. S. \& FinerTy, J. P. (1967). Induction of mitotic recombination in Saccharomyces cerevisiae by ethylmethane sulphonate. Nature, London 215, 660-661. 